\title{
THE ATID PROJECT: TEACHING THE HOLOCAUST THROUGH DIGITAL STORYTELLING
}

\author{
by \\ Eli Kowaz \\ BA (Hons), McGill University, 2013
}

\begin{abstract}
A Major Research Paper
Presented to Ryerson University
\end{abstract}

in partial fulfillment of the

requirements for the degree of

Master of Digital Media

in the

Yeates School of Graduate Studies

Toronto, Ontario, Canada, 2015

(C) Eli Kowaz 


\begin{abstract}
AUTHOR'S DECLARATION
I hereby declare that I am the sole author of this MRP. This is a true copy of the MRP, including any required final revisions.

I authorize Ryerson University to lend this MRP to other institutions or individuals for the purpose of scholarly research.

I further authorize Ryerson University to reproduce this MRP by photocopying or by other means, in total or in part, at the request of other institutions or individuals for the purpose of scholarly research.

I understand that my MRP may be made electronically available to the public.
\end{abstract}

Signed,

Eli Kowaz 


\begin{abstract}
This paper aims to develop a Holocaust education protocol template with the goals of maximizing student engagement, enhancing the student experience, boosting retention of information, and facilitating the individual's identification with the historical events of the Holocaust. The protocol proposed is of general application and is suitable for other current and historic events. At the same time, the Holocaust is a powerful and appropriate event for illustrating the impact of digital media on education, and in particular, it highlights head on the issue of historical distance from actual events and the ways in which digital technology and media can reduce the risk of losing key sources of testimonial experience that are so often central to the student's appreciation and understanding of such events. This proposed conceptual protocol is founded on three basic dimensions: Content, Learning Sequencing, and Digital Media. These dimensions are interactive and overlapping in the proposed model.
\end{abstract}




\section{ACKNOWLEDGEMENT}

I would like to acknowledge my advisor, Professor Jason Boyd, for his commitment and guidance. This paper would not be possible without his wisdom and knowledge. Also, my second reader Professor Michael Carter, for his dedication and counsel. 


\section{DEDICATION}

To the victims of the Holocaust, the millions of innocent people who lost their lives because of their beliefs, sexual orientation, religion, or their will to fight evil. To the survivors, many whom are no longer with us, most of whom lost their entire families and spent their lives telling stories and educating others in order to preserve the memory of those who perished and, ensure the events that transpired will never be repeated, to the victims of genocide around the world, who have suffered from the most barbaric acts of man and lastly, to my grandmother the late Dr. Sally Rogow, who spent her life helping those in need, writing, teaching, and fighting for an equal and just society, publishing over dozens of peer reviewed journals, articles, and books, two of which focused on brave heroes of the Holocaust. 


\section{TABLE OF CONTENTS}

Author's declaration ............................................................................................................ ii

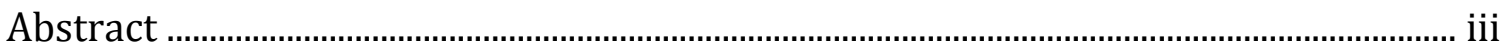

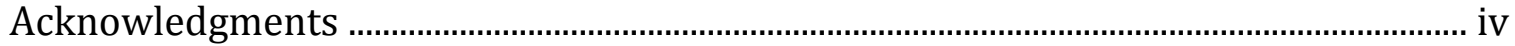

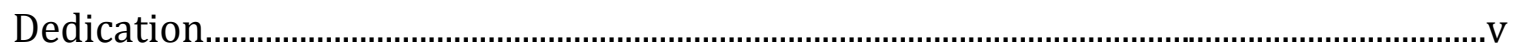

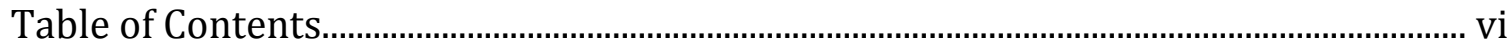

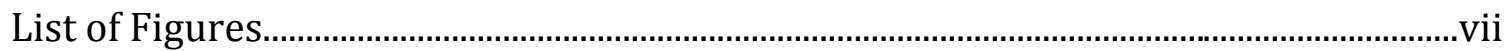

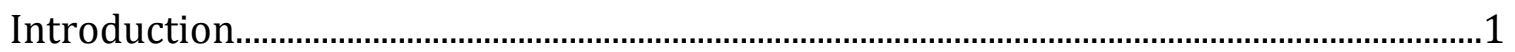

Digital Media in Current Holocaust Education...........................................................................

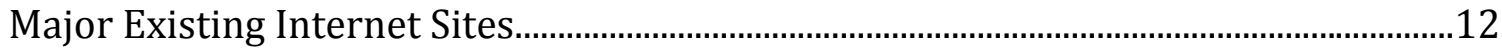

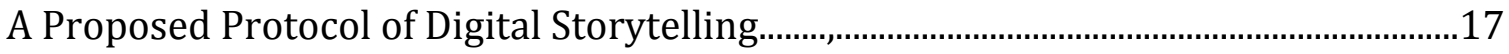

Dimension One: The Content.................................................................................................

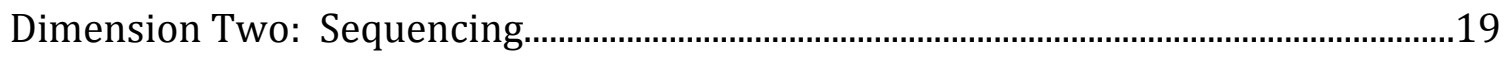

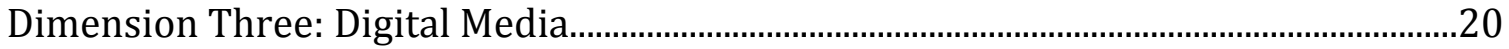

Key Components of a Digital Story Telling Model............................................................22

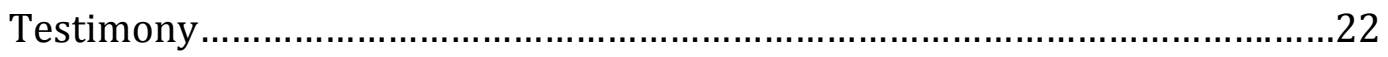

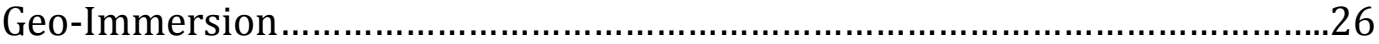

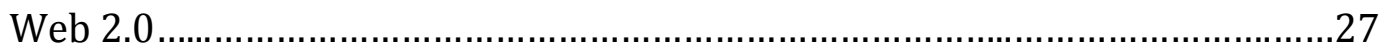

Google \& Dynamic Digital Mapping .......................................................... 31

Summary of the Proposed Model..................................................................................................

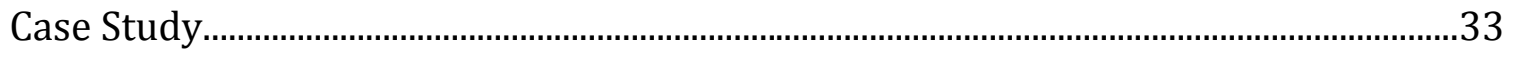

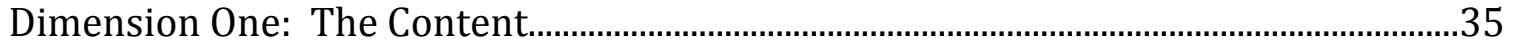

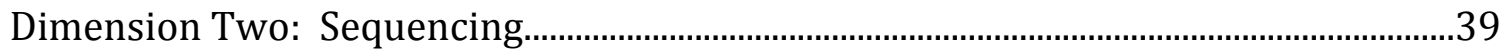

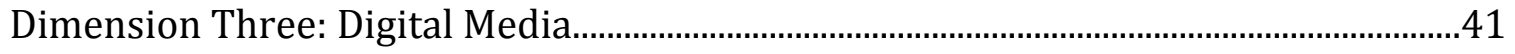

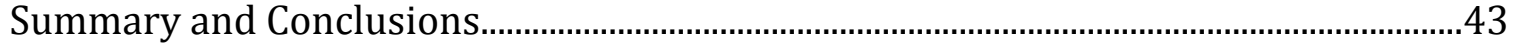

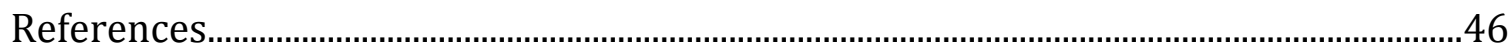




\section{LIST OF FIGURES}

Figure 1/ Yad Vashem's Thematic and Chronological Narrative of the Holocaust..........14

Figure 2/ The USHMM's Web Homepage.................................................................... 15

Figure 3/ An Online USHMM Encyclopedia Article..............................................16

Figure 4/ Holocaust Education Through Digital Storytelling: The Cube.........................18

Figure 5/ The Digital Storytelling Cube of Pinchas Gutter..........................................34

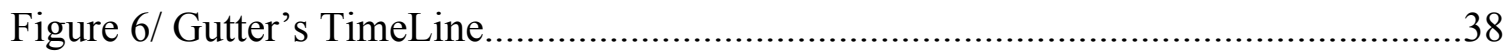

Figure $6 a$.

Figure 6b.

Figure 6c. 


\section{INTRODUCTION}

From 1941 to 1945 , the Nazis systematically murdered six million Jews, killing approximately two-thirds of the European Jewish population. In addition, they murdered approximately five million non-Jews including Gypsies, Poles, homosexuals, the mentally and physically disabled, political opponents, and prisoners of war (Baumeister, 2002;241). The methodicalness and scale of this atrocity, commonly referred to as the Holocaust, are hard to comprehend. How one of the most advanced and civilized nations of Europe was able to commit such heinous acts of organized mass murder is still difficult to grasp. This only happened seventy years ago. A quick perusal of today's news stories suggest that the worst aspects of humankind, so aptly illustrated by the Holocaust, continue to find expression. While the magnitude of the Holocaust is much greater than these events, there is no shortage of atrocities in our modern world.

The horrors of the Holocaust teach the dangers of silence and indifference, while emphasizing the value of living in society where our rights and personal beliefs are protected. Many survivors have recognized the importance of telling their stories as a means of honouring their families and other victims, and as a means of educating future generations. As Holocaust survivors pass on, the debate about how to teach the Holocaust intensifies, in particular, the most effective method of preserving survivor testimonies for educating future generations.

This comes at a time when in many countries, astonishingly, the historical reality of the Holocaust is being questioned; a 2014 survey from the Anti-Defamation league found that only 54 percent of the global population has heard of the Holocaust, and only a 
third believes the Holocaust has been described accurately (Green, 2014). A popular BBC television program, Big Questions, recently did a show on the question 'Is it Time to Lay the Holocaust to Rest?'(Koren, 2015), and in 2006 Iran hosted an international Holocaust denial conference (Fathi, 2006).

When prominent American historian Deborah Lipstadt published a book condemning Holocaust denial, Denying the Holocaust: The Growing Assault on Truth and Memory (1993), she found herself being sued for libel by one of the most dangerous Holocaust deniers, David Irving, who, at that time, had a reputation as a meticulous historian. After a highly publicized trial, Irving was subsequently convicted for deliberately misrepresenting and distorting historical evidence (Irving v. Lipstadt, 2000). This case represents the continual threat to the truth of the Holocaust by those who wish to question the evidence provided by survivor testimony and historical documentation. At the conclusion of the trial, Professor Lipstadt said "I see this not only as a personal victory, but also as a victory for all those who speak out against hate and prejudice" (Busfield, 2000). Her subsequent book describing this experience is aptly titled: History on Trial. The dangers of Holocaust denial make finding an effective method of Holocaust education in the post-survivor era all the more critical.

Professor Yehuda Bauer of Hebrew University explains that when it comes to Holocaust education, the most important thing is the relevance of the topic to the lives of those being educated (Bauer, 2012). That relevance is determined not only by the content of the message, but how it is delivered. A McGraw-Hill study (2015) surveyed 1,697 college students and found that digital technology is an essential part of study for the 
majority of students. The study found that 81 percent of students use mobile devices to study, 62 percent of students say technology helps them feel better prepared, while 77 percent believe adaptive technology has helped them improve their grades. A 2012 study by the National Literary Trust in the UK found that "technology-based formats, such as text messages (68.4\%), websites (53.2\%) and messages on social networking sites (51.1\%) are most commonly read outside of class at least once a month" (Clark, 2012). This evidence is compelling, and shows a clear trend towards digital technology as the most effective way of engaging young people.

With survivors passing away, much of the immediacy and impact of testimony is lost and therefore it is essential to find the most effective way to preserve testimony in order to memorialize the Holocaust and educate future generations. Digital storytelling tools are uniquely suited as the medium for recording and preserving this important firsthand source as new technologies, such as holographic 3-dimensional recordings of survivors, allow us to record and present testimony in ways never thought possible. Using these tools in educational settings is important but it is crucial to do so in a responsible and specific manner. As Don Tapscott argues, "Don't throw technology into the classroom and hope for good things. Focus on the change in pedagogy, not the technology. Learning 2.0 is about dramatically changing the relationship between a teacher and students in the learning process" (2008:140).

This paper aims to develop a Holocaust education protocol template with the goals of maximizing student engagement, enhancing the student experience, boosting retention of information, and facilitating individual identification with the historical 
events of the Holocaust. In doing so, I will first highlight the role of digital technologies currently being used in the Holocaust memorial landscape, including a survey of two major internet web resources on Holocaust memorial and education, Yad Vashem and the USHMM (United States Holocaust Memorial Museum). After a critique of these sites, I will outline an educational protocol after a careful review and analysis of the newest technologies and developments in Holocaust education. including the simulation of survivor testimony through Holograms, Web 2.0 affordances, and geo-immersion.

\section{DIGITAL MEDIA IN CURRENT HOLOCAUST EDUCATION}

The role of digital technologies in the teaching of the Holocaust and the communication of Holocaust memory is important for achieving educational objectives related to this important historic event. In addition, it serves as an important vantage point from which to observe the role of different media in the communication of the memory of important events more generally. Anna Reading explains: "Focusing on how the memory of the Holocaust is being articulated by new technologies in public spaces can provide important clues for understanding the relationships between media, culture and memory that, in turn, can enable reflection on the role of different media and socially inherited memories in current events and subsequent atrocities" (2003:71).

Significant online educational resources on teaching the Holocaust are available in North America and Europe, resources which include the websites of the two most well-known Holocaust museums (in Washington DC and Jerusalem). As Reading explains, "Holocaust memory has become configured within museum environments in virtually every community worldwide in which Jewish people and other Nazi displaced 
persons were forced to re-settle. One of the earliest of these museums to be established was Yad Vashem: the Holocaust Martyrs and Heroes Remembrance Authority in 1953 created by an act of the Israeli Knesset in Israel" (Reading, 2003;70). She also notes that in the United States, "15 years after President Carter established the Commission on the Holocaust, the US Holocaust Museum was opened on prime land in Washington, DC" (Reading, 2003;70). Since its opening in Washington, D.C., the US Holocaust Memorial Museum has welcomed almost forty million visitors, including ten million children and ninety-six heads of state (About the Museum, USHMM). The museum's "primary mission is to advance and disseminate knowledge about this unprecedented tragedy; to preserve the memory of those who suffered; and to encourage its visitors to reflect upon the moral and spiritual questions raised by the events of the Holocaust as well as their own responsibilities as citizens of a democracy" (Mission Statement, USHMM). Museums are especially significant because, unlike archives, they have a mission to engage the public with the historical evidence. Yad Vashem opened in 1953 and is the second most frequently visited tourist destination in Israel. Its new exhibition space was opened in 2005 and was designed by renowned Israeli-Canadian architect Moshe Safdie. It houses the largest collection of artwork from the Holocaust and has collected approximately 110,000 audio, video, and written testimonies of Holocaust survivors (Yad Vashem Archive). The new museum embraced the ideal of integrating digital technology into the Holocaust memorial and educational experience. There are more than 140 flat-panel displays, and 130 video streams fully integrated into the exhibit. There are 
dozens of projectors and the museum's entrance features Michal Rovner's video art projected on a 14-metre high triangular screen (Avitecture, 2005).

These museums were the first to integrate digital technology into Holocaust memory and education. As Reading notes, "public institutions such as museums, web-sites and interactive digital media consoles are also increasingly part of the memorial landscape" (2003:67). Reasons for this are two-fold. First, museum organizations have been quick to recognize the possibilities provided by new technologies and second, as survivors age, museums have recognized that it is essential to "find ways of tactfully retaining survivor's stories in the form of digital interactive multimedia consoles located in the exhibition space" (Reading, 2003;71).

Museums exist beyond the borders of Israel and the United States. Holocaust museums can be found Argentina, Australia, Canada and South Africa. In Asia, there is an exhibition in Shanghai, and in Japan there are Holocaust Education Centres in Tokyo and Fukuyama City (Reading, 2003). In Europe, concentration and death camps that the Nazis were not able to destroy have been preserved and many have been turned into museums or memorials. Auschwitz-Birkenau is a UNESCO world heritage site and had more than 1.5 million visitors in 2014 (Payne, 2015). Reading (2003) observes that while many of these Holocaust museums are still primarily artifactual, there has been a strong movement towards using new technologies and digital interactivity. The Simon Wiesenthal Center's Museum of Tolerance in Los Angeles was one of the first to develop this powerful approach. It was "established with the view that new technologies could provide young people especially with important new ways of learning about the events" 
(Reading, 2003;71). The centre devotes "almost an entire floor to its Multi-media Learning Center" and "digital interactivity in a variety of forms has been at the heart of the museum's philosophy since it opened in 1993" (Reading, 2003;71). The Los Angeles Museum of the Holocaust also focuses on the digital storytelling experience: its digital innovations were completed by Variate Labs, a design film specializing in architecture and interaction design. The exhibition wall and touchscreen monitors, improved audio guides with more user controls, and traditional photographic and object-filled exhibits are all a testament to the recognition of the significance of the digital storytelling experience within the confines of the museum. Lester explains, that by digitizing museums "the immersive experience becomes individualized" (2013:247).

For those fortunate to have a museum or education centre close by, school visits are a powerful way to teach the Holocaust; but for many if not most school-age children, this is not possible. For this reason, it is essential to bring a specific method of teaching the Holocaust through digital storytelling to the classroom. As Meghan McGlinn Manfra and Jeremy D. Stoddard argue, "digital resources have the potential to enhance genocide and Holocaust education by providing robust content resources and interactive opportunities for students to develop new skills and understanding" (2008:260). In Holocaust education, a key goal includes the retention of the events as experienced by survivors and in educating future generations about its magnitude and impact. According to its director, Douglas Greenberg, the Shoah Visual History Foundation has recorded 51,721 video testimonies of Holocaust witnesses and survivors, while developing digital interactive systems that allow researchers to call up computer 
extracts of digitized video testimonies on indexed subjects (as cited by Reading, 2003;67).

Thus while new forms of media have become a part of Holocaust education, and resources abound, the integration of digital media has occurred at a slow pace and has not fully capitalized on the full power and potential of digital media and technology. Many Holocaust education websites provide survivor testimony using plain text, while YouTube videos of testimony are often long, unedited and not identified as to target groups or intended audience, not to mention the challenges of Holocaust education in particular with the the dependency on face-to-face survivor testimony, the sensitivity of the topic, and the vast resources available. In emphasizing these challenges, D. Crowe (2001) explains that the resources available are "massive and daunting" (Manfra \& Stoddard, 2008;260).

It is also important to emphasize that a key element of Holocaust education is preventing future genocide. James Brown (2007) provides an example of the complexity of teaching genocide in the $21^{\text {st }}$ century. While his example centres on Darfur, his observations are generalizable to the Holocaust and other genocidal atrocities. Brown describes freshman university students playing the role of refugees in a simulation of a refugee camp in Darfur, Sudan. Darfur, a region in southwestern Sudan, was the site of the most deadly genocides since the Holocaust. Government-funded Arab militias known as the Janjaweed killed more than 300,000 people according to UN estimates, leaving approximately 3.2 million people displaced (Darfur Conflict, 2014). Though intended to leave the students with an affective experience from which they would learn, the 
designers of the simulation, in Brown's view, trivialized the experiences hundreds of thousands and refugees. Brown states:

One of the students volunteered to go up on stage and demonstrate the "Darfur is Dying" computer-based simulation that had been projected onto a large screen. (1) She selected one of the eight members of a family in Darfur portrayed in the simulation to "forage for water." As the student used the computer keys to help the female animated character, "Sittina," race across the desolate wasteland in search of water, the audience cheered wildly. They shrieked as the Janjaweed truck came creeping closer, roared approval as the character ran to evade the militia, and booed at her inevitable capture. At this point, the simulation queried if we would like a chance to try again. The audience clamored, "Yes!" and so another family member was selected, this time a child named "Abok." This cartoon figure was much faster, and glided across the screen, to the delight of the crowd, but ultimately met the same fate as Sittina. As the simulation ended, students applauded enthusiastically. (Brown, 2007;21)

Afterwards, Brown was unsure if this was the appropriate way to teach genocide even if it increased awareness. He writes: "I sat in my chair, disturbed, questions racing through my head: Is this the way to teach issues such as genocide in a new millennium characterized by new technologies? Is this how we reach students who have grown up playing video and computer games? Do these technologies provide a new opportunity for activism and understanding? It may be that the answer to all of these questions is "yes," but ethical questions do arise. Is it acceptable to trivialize a tragedy (of a massive scale) through a game so that awareness is increased? Should we make the study of history more game-like? What are the limits of simulations?" Brown recognized the importance of digital media in engaging and motivating students to learn about genocide, but hoped teachers would instead "use new technologies [that] will help students to access authentic information from primary sources, which we may have only been able to simulate in the 
past" (2007:23). This example highlights a danger lurking in the adoption of digital technology without comprehension of the current generation's exposure to gaming and other aspects of the digital experience that may create a challenge in differentiating real events from those of the imagination (or in the imagination of gaming designers). Brown is describing how his students may have distanced themselves from the experience of Darfur, just like they are accustomed to do in their use of digital technologies for precisely the objective of escape and fantasy. This reality has to be appropriately acknowledged and addressed in the use of digital technology for teaching about real historic events and individuals who experienced them. Planned and well thought out applications of digital media in the teaching of difficult historical events is critical, and is all the more important, given the potential intensity of the audience experience with regard to difficult content.

Fred M. Newmann and Gary G. Wehlage's (1993) framework for "authentic instruction" provides a valuable resource for effective social studies education using new digital technologies. Manfra and Stoddard (2008) explain that this framework is particularly effective because it "suggests specific criteria for meaningful social studies teaching and learning and reflects the purposes of the affective revolution-era curriculum.” The framework they suggest is comprised of three main components:

(1) student construction of knowledge through the engagement of higher-order thinking skills, including interpretation, analysis, and synthesis; 
(2) student engagement in disciplined inquiry that leads to a depth of knowledge and engagement in substantive conversations, modeled after social science professions;

(3) student engagement in making connections to the world beyond school. Manfra and Stoddard suggest compiling a variety of "available resources to identify digital media that engage students in moral and ethical valuing, emphasize historical inquiry, and are relevant to the world outside of school (e.g., taking action to thwart present-day genocide)" (2008:260).

Importantly, Manfra and Stoddard focus on using "new media to demonstrate ways to teach authentically about genocide and the Holocaust" while acknowledging "the importance of text-based and photographic Web-based resources currently available" (2008:261). The Holocaust provides an opportunity to model the optimal use of digital media in achieving educational goals at a crucial intersection: availability of vast digital resources and technologies and the timeliness of availability of face-to-face survivor testimony. The value and timeliness of face-to-face survivor testimony is an essential dimension of the teaching of the Holocaust. Yet even among those who are willing to share their stories, health issues and other aspects of aging are becoming an increasing challenge. Manfra and Stoddard explain that "this decline has led to a number of digital media projects that capture the stories of survivors and make them available via streaming audio or video" (2008:261).

Unfortunately, from the perspective of these researchers, turning to digital technology as an effective education tool in teaching the Holocaust has predominantly 
been a reactive process, meaning museums and educators have turned to technology only because the difficulty of direct access to survivors. As Reading explains in reference to the role of digital interactive technology in Holocaust exhibits, this "area of inquiry has been virtually ignored by scholars in the field of Holocaust studies" (2003:71).

\section{MAJOR EXISTING INTERNET SITES}

After extensive research of online Holocaust Museum educational resources, it is clear that two stand above the rest: the educational section of the website of Yad Vashem in Jerusalem, and the website of the US Holocaust Memorial Museum in Washington, DC. Yad Vashem is the most content heavy of online Holocaust education resources. The website features a database of Holocaust victims, and an extensive online photo and document archive. The site also features a video testimony resource centre and a film archive. The website is full of primary sources.

For basic historical coverage, Yad Vashem offers a Thematic and Chronological Narrative of the Holocaust. This webpage features a side tab with title and subtitle links in chronological order describing the history of the Holocaust from 1933 to the conclusion of the Nuremberg Trials. The content is good, but it is text heavy: every page features only one small image, and the remainder is text (Figure 1). Each article is engaging and well-written, but the question arises about its ability to keep a $21^{\text {st }}$ century student engaged. The problem with this and many other such websites is that the abundance of content at their disposal makes it difficult to present an engaging online story. Another impressive part of the Yad Vashem online resource is their video 
collection, in particular its YouTube channel, where there are over 1100 videos posted. These include survivor testimonies, an educational tool kit series featuring video tutorials advising teachers how to approach different Holocaust topics, virtual tours of different exhibits in the museums, and mini-documentaries. All of these videos are important and most are arranged in playlists; however, maneuvering between the collection of more than a thousand videos is difficult because in many cases they are not connected using common themes, indexed by a keyword, or in the language of the person conducting the search (Gray, 2014). Gray argues that it is important these resources be "made user-friendly for both teachers and students alike, so that they can search and select the appropriate testimonies quickly and easily" (2014:112). 
Figure 1 Yad Vashem's Thematic and Chronological Narrative of the Holocaust The Holocaust

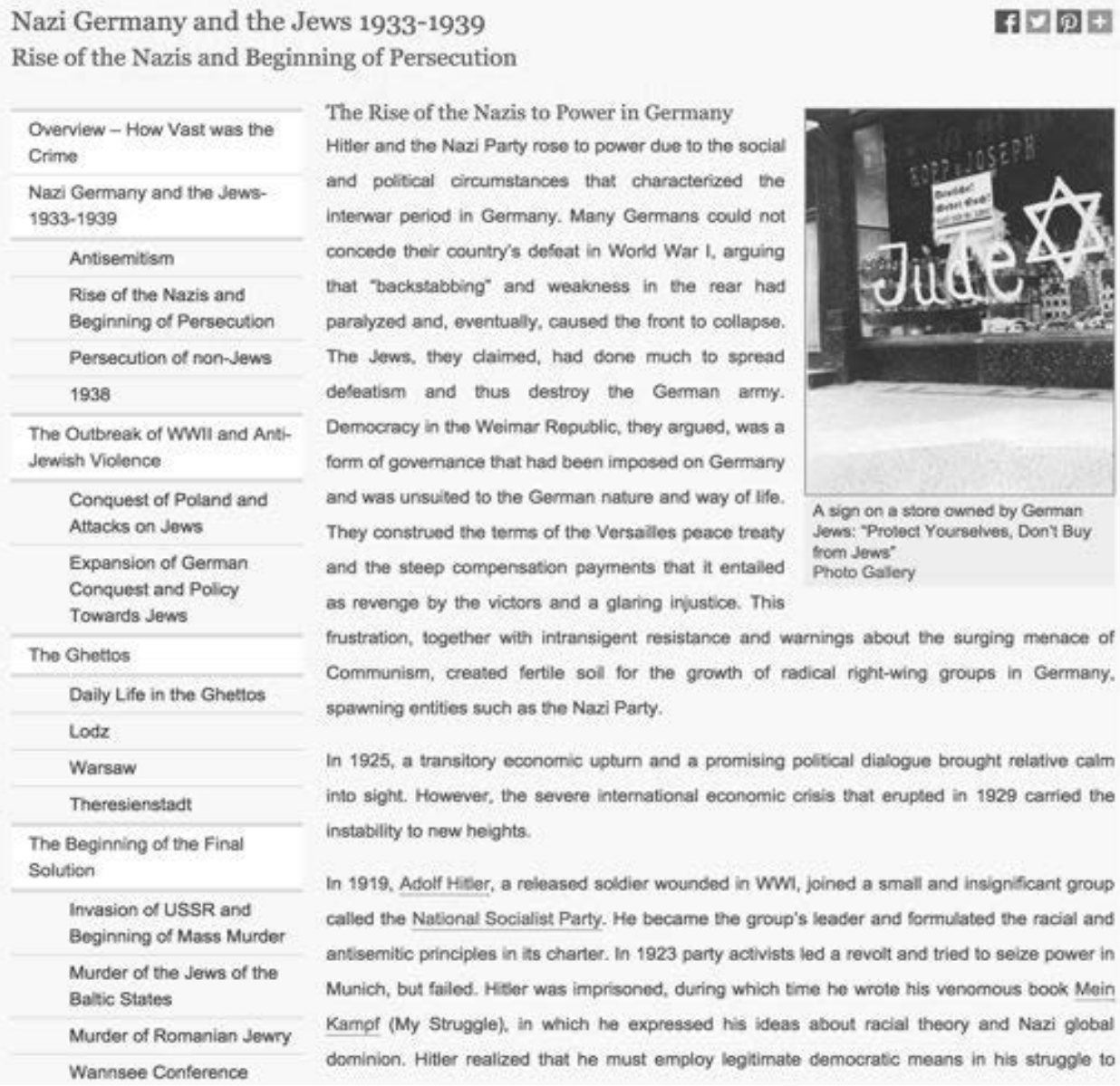

The Rise of the Nazis to Power in Germany Hitter and the Nazi Party rose to power due to the social and political circumstances that characterized the interwar period in Germany. Many Germans could not concede their country's dofoat in World War $\mathrm{L}$, arguing that backstabbing' and weakness in the rear had paralyzed and, eventually, caused the front to collapse. The Jews, they claimed, had done much to spread deleatism and thus destroy the German army. Democracy in the Weimar Republic, they argued, was a form of govemance that had been imposed on Germany and was unsulted to the German nature and way of life. They construed the terms of the Versalles peace treaty and the steep compensation pryments that it entaled as revenge by the victors and a glaring injustice. This

A sign on a store owned by German Jems: - Prolect Yourselves, Dany Buy

Photo Gallery frustration, logether with intransigent resistance and warnings about the surging menace of Communism, created fertile soll for the growth of radical right-wing groups in Germany. spawning ontities such as the Nazi Party.

In 1925, a transitory economic upturn and a promising political dialogue brought relative calm into sight. However, the severe international economic crisis that erupted in 1929 carried the instability to new heights.

In 1919. Adolf Hitler, a released soldier wounded in WWI, joined a small and insignificant group called the National Socialist Party. He became the group's leader and formulated the racial and antisemitic principles in its charter. In 1923 party activists led a revolt and tried to seize power in Munich, but failed. Hitler was imprisoned, during which time he wrote his venomous book Mein Kampf (My Struggle), in which he expressed his ideas about racial theory and Nazi global dominion. Hitler realized that he must employ legitimate democratic means in his struggle to

Another leading institution with a significant online presence is the United States

Holocaust Memorial Museum (USHMM) in Washington, DC. Unlike Yad Vashem, the front page is captivating and clear (Figure 2). The website features a Holocaust encyclopedia which has been translated into 14 different languages. 
Figure 2 The USHMM's Web Homepage

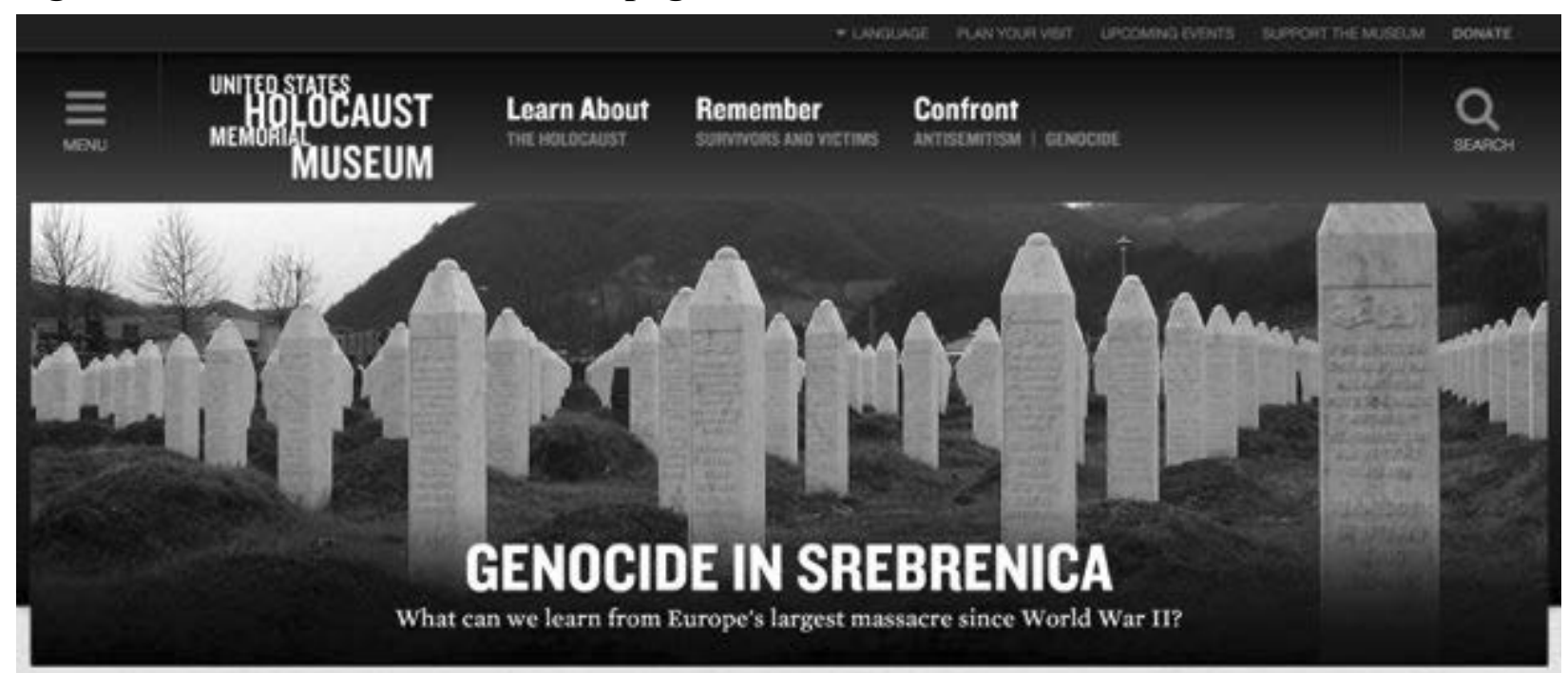

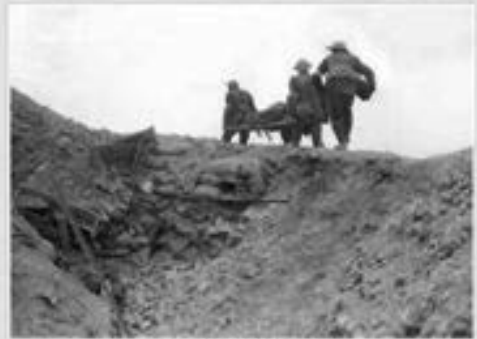

ENCYCLOPEDIA

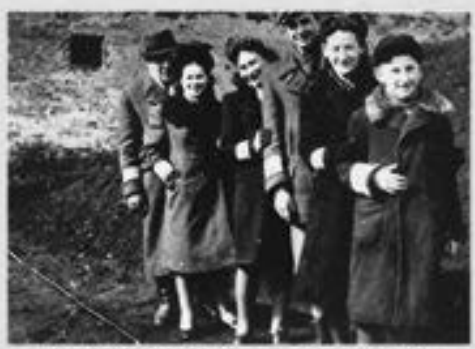

INTRODUCTION TO THE HOLOCAUST

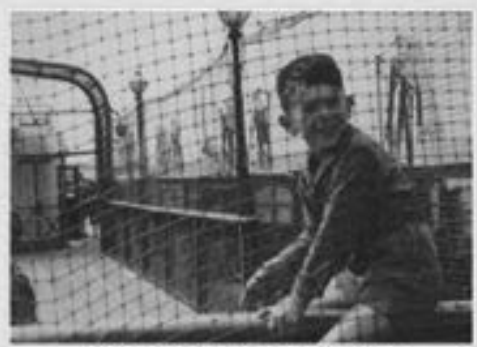

RESOURCES FOR EDUCATORS

Similar to the Yad Vashem site, the text from the Encyclopedia articles is very heavy (Figure 3). A significant difference is that the sidebar of many articles invites viewers to watch historical video footage, and view photographs relevant to the article being viewed. This is beneficial; however, the influence is on plain text and not the interactive elements of the site. 


\section{Figure 3 An Online USHMM Encyclopedia Article}

\author{
Hitler estabished a Reich Ministry of Public \\ Enlightenment and Propaganda headed by \\ Joseph Goebbels. The Ministry's aim was to \\ ensure that the Nazi message was \\ successfully communicated through art, \\ music, theater, films, books, radio, \\ educational materials, and the press.
}

There were several audiences for Nazi propaganda. Germans were reminded of the struggle against foreign enemies and Jewish subversion, During periods preceding legislation or executive measures against Jews, propaganda campaigns created an atmosphere tolerant of violence against Jews, particularly in 1935 (before the Nuremberg Race Laws of September) and in 1938 (prior to the barrage of antisemitic economic legislation following Kristallnacht). Propaganda also encouraged passivity and acceptance of the impending measures against Jews, as these appeared to depict the Nazi government as stepping in and "restoring order."

Real and perceived discrimination against ethnic Germans in east European nations which had gained territory at Germany's expense following World War I, such as Czechoslovakia and Poland, was the subject of Nazi propaganda. This propaganda sought to elicit political loyalty and so-called race consciousness among the ethnic German populations. It also sought to mislead foreign governments -including the European Great Powers-that Nazi Germany was making understandable and fair demands for concessions and

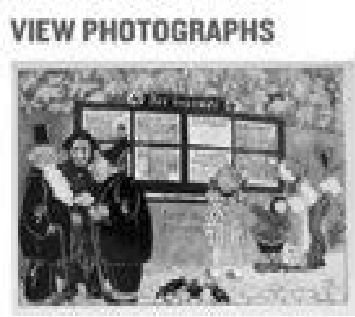

VIEW HISTORICAL FILM FOOTAGE

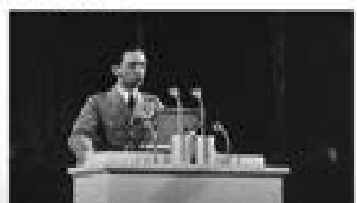

These two websites were selected because of the solid reputation of their respective organizations, their efforts to integrate digital technology into the framework of Holocaust education, and the digital and nondigital resources available. It is clear that both Museums have invested a great deal in digitizing primary historical content and making them available on the Web; however, they are not maximizing the digital 
affordances, nor are they making the connection between their content and how young people are using digital technology.

A review of these and the USC Shoah Foundation at The Institute for Visual History and Education (http://www.vhf.org/) supports the rationale for the current paper and its objective of developing an educational protocol that will maximize the goals of student engagement, enhancing the student's experience and retention of information, and facilitating the individual's identification with the important historical events of the Holocaust. This protocol is especially important because keeping the Holocaust relevant will become increasingly more difficult as time passes and as survivors pass on.

\section{A PROPOSED MODEL OF DIGITAL STORYTELLING}

This paper proposes an education protocol with the specific goal of effectively linking digitized historical content and young people's interaction with digital technology. The protocol will consequently maximize student engagement, enhance the student experience, boost retention of information, and facilitate the individual's identification with the historical events of the Holocaust. As Michael Gray argues "it is imperative that sufficient training is available for practitioners so that they can become confident and savvy in their use of the technology" (Gray, 2014;120). Yet the training that occurs needs to go beyond simply showing how the programmes and software work, but how they can be best employed to fulfil the specific goals of Holocaust education" (Gray, 2014;120). 
This protocol is founded on three dimensions: Content (academic resources, testimony, evidence), Learning Sequencing (importance of timing and sequencing of the learning experience) and Digital Media (the use of modern day digital technology in all its forms). These dimensions are interactive and are not mutually exclusive (Figure 4).

Figure 4. Holocaust Education Through Digital Storytelling: The Cube.

\section{Sequencing}

Sequencing of the various elements as a key factor in achieving the goals of the protocol, including ethical consideration reflecting the sensitivity of the material.

- Pre and post storytelling activities.

- Sequencing of the story itself.

\section{Digital Media}

\section{Content}

Enhancing the experience of the storytelling.

- Film

- Photos

- Maps

- Music

- Video Footage

- Digital Documents
Effective and efficient use of the vast amount of available Holocaust resources.

- Academic Resources

- Testimony

- Evidence

\section{These domains are not mutually exclusive, and interact} throughout the learning experience. 


\section{DIMENSION ONE: THE CONTENT}

Content gives us the resources to tell the story. Content includes academic resources and research, testimony, and other sources of evidence. In the proposed protocol, the main objective of this dimension is the effective and efficient use of the vast amount of available Holocaust resources.

The landscape with regards to content is vast and includes thousands of archives and scholarly publications much of which is preserved in museums, universities, and other educational institutions. The challenge is to make use of this content to effectively and efficiently engage the $21^{\text {st }}$ century student. For this reason, many institutions have put significant resources into improving their web presence.

Academic resources are comprised of predominately reading material from scholarly research to relevant books: these resources give us the academic support to tell the story. Testimony comes in different forms: written, recorded audio, and video testimony. Testimony is an indispensable resource: not only does it tell us the story of Holocaust survivors and victims, but it integrates the History with personal stories. Other evidence includes the vast amount of documents, photographs, video footage, audio recordings, and all physical remnants from the Holocaust.

\section{DIMENSION TWO: SEQUENCING}

The next dimension of the protocol is Sequencing. This involves sequencing of the various elements as a key factor in achieving the goals of the protocol, including ethical considerations reflecting the sensitivity of the material. This dimension deals with 
the actual unfolding of the story, including attention to what comes first, what comes last and what kind of preparation the participant needs before exposure to the story itself, such as preliminary readings or discussions.

It is useful to review some ethical considerations inherent to the teaching of difficult materials, such as the magnitude of human suffering in the Holocaust and other atrocities, and the dimension of sequencing puts this into primary focus. As an example, it is important to ensure that students are aware of the nature of the film clips and story content through preparatory summaries and readings, as well as addressing this directly through digital media, so that students are prepared. Equally important is building into the sequencing appropriate follow up to allow for discussion and debriefing after hearing or viewing some of the more difficult content. The objective of this dimension is to ensure that the preparation and follow-up provide the appropriate support so that the actual digital experience is appropriate and effective in reaching the learning objectives.

\section{DIMENSION THREE: DIGITAL MEDIA}

The third dimension of the cube is Digital Media, which in this protocol is seen to be the means of achieving the important objective of enhancing the experience of the storytelling and the experience of the student through the use of digital media and technology. This includes all the resources that have been digitized along with new technologies that can be integrated to the story. As Yehuda Bauer (2012) emphasized, the most important part of Holocaust education is to make what is learned relevant to the lives of the students. To do this effectively it is imperative to integrate digital media with proven information processing and educational methods. 
The 21 st century student is different from students of previous generations. As Don Tapscott describes, "The Net Geners (21st century students) have grown up digital and they're living in the twenty-first century, but the education system in many places is lagging at least 100 years behind. The model of education that still prevails today was designed for the Industrial Age. It revolves around the teacher who delivers a one-size-fits-all, one-way lecture. The student, working alone, is expected to absorb the content delivered by the teacher" (2008:22).

This integration of digital media will help facilitate a shift in focus from the teacher to the student. Tapscott argues that this shift is needed to teach effectively in the 21st century: "instead of focusing on the teacher, the education system should focus on the student. Instead of lecturing, teachers should interact with students and help them discover for themselves. Instead of delivering a one-size-fits-all form of education, schools should customize the education to fit each child's individual way of learning. Instead of isolating students, the schools should encourage them to collaborate" (2008:122). Tapscott explains that "to focus on the student, educators must abandon the old system in which the teacher delivers the lecture, the same lecture to all students" and "encourage students to discover for themselves, and learn a process of discovery and critical thinking instead of just memorizing the teacher's information" (2008:130).

One of the most concerning observations with regards to Holocaust education is that "teachers [in the US] are uncomfortable using technology and are unaware of all it offers, both to increase their own historical knowledge and to create learning activities for 
students" (JESNA, 2006). This protocol provides a clear framework intended to give teachers the confidence to adopt digital storytelling into their Holocaust curriculum.

\section{KEY COMPONENTS OF A DIGITAL STORY TELLING MODEL}

This section describes key components to a digital story telling model in Holocaust education. In doing so, it will make reference to the research literature and highlight both the strengths, weaknesses, and potential pitfalls.

\section{Testimony}

Holocaust testimony is one of the most interesting aspects to be integrated into an effective digital storytelling method. Hearing the story from a survivor face-to-face is deeply moving, raw and unfiltered. As Sheryl Ochayon (2015) explains, survivor "voices resonate with the authority that comes from their personal experiences" $(0: 15-0: 20)$. Survivors act as the "human bridge that connects us to the events that occurred in the past" (0:22-0:27). Ochayon comments that with the passing of survivors, "we will lose much of the immediacy and impact that comes from their testimony" (0:38-0:43). This is why it is imperative to use recorded testimony in appropriate context, striking a balance between the history and the emotional experience of hearing the story. As Ochayon explains, "In a world where survivors no longer walk among us, it will be critical to use survivor's testimony in the classroom to bring students closer to the human stories of the Holocaust" (0:47-0:55). Due to its importance in Holocaust education, substantial effort had been invested in creating ways testimony can survive after the survivors themselves are gone. One important resource is the Iwitness program. The program provides access 
to teachers to the video testimonies along with an activity building feature. The program facilitates the integration of testimony into the classroom in many ways, allowing students to actively engage with the process and content. The program enables students to produce media projects with a built-in video editing system (Gray, 2015). This is a significant step in integrating technology into Holocaust education and is similar to digital storytelling as it means "students can engage with the medium to find out some of the answers to their questions" (Gray, 2015;61). In another interesting project, the University of Southern California Shoah Foundation collaborated with smartphone app Broadcastr. The app provides users with relevant content based on their location. This technology was adapted to Holocaust education and the app allows students to hear Holocaust testimonies from the USC Shoah Foundation's testimony collection based on the location of the user (Gray, 2015). If a student was visiting Lodz in Poland, for example, testimonies from the city would be available to download.

Wolf Kansteiner, Professor of History at Binghamton University, explains that the "culturally constructed aura of the Holocaust survivors has been a crucial component of Holocaust education in the past decades" and that "for the future of Holocaust memory, it is important that that aura gets a second lease on life or is replaced by a similarly attractive memorial focus" (2014:404). The most notable attempt in this direction is the New Dimensions in Testimony project. The project aims to create an interactive connection between the survivor and the student, an imperative in teaching the Holocaust in the 21 st century (Gray, 2015). The project has recorded survivor testimony in a 26-foot spherical stage, lit by over 6,000 LED lights, producing a hologram projection (Gray, 
2015). The aim of the project is to create "an environment in which an individual or an entire class can have a survivor sit with them to tell his or her story, via video or project; they will be able to ask questions and the survivor will answer from the testimony as if he or she were in the room" (Maio et al. 2012;24).

Taken at face value, this project appears to be an effective solution to preserving survivor testimony and presenting it to future generations. It is timely as well. According to a report from The Tauber Holocaust Library and Education program in San Francisco, approximately 500,000 Holocaust survivors are still alive, yet 6-10 percent of those die annually, and their average age is 79 . Clearly the challenge of finding living survivors who would be physically able or willing to tell their story in such detail becomes more critical with each passing year. Kansteiner explains that "the holograms of survivors are very good at mastering the past; in simulated conversation, they seemingly spontaneously provide the details of their family histories, camp ordeals, survival strategies, and postwar lives" (2014:404).

While this is compelling, it is important at this juncture to examine the possible challenges and pitfalls of this potentially powerful digital tool. Recall the result of Brown's in-class simulation, where students played the role of refugees in a simulation of a Darfur camp; there are pitfalls in using simulation technologies in the classroom. As sophisticated as the technology is, it is a simulation and not a real engagement with a person. As Kansteiner explains, the survivor holograms “cannot handle the present; don't ask them what they had for breakfast today. At some point during the communicative process, the ingenious hybrid of dialogical questions and monological answers breaks 
down" (2014:404). This breakdown is concerning and raises the prospect of confusing or "turning off" the students, and perhaps even making them question whether the simulation's presentation of the testimony is authentic. Further, such technologies will not be able to reproduce the same emotional experience of spending time with a survivor. This raises the importance of finding a way to approximate authentic survivor face-to-face testimony that in itself does not undermine the intention of using this technology. Kansteiner makes an important point that "despite their technological sophistication, the holograms cannot be effectively and continuously brought up to date; they will likely always carry small, yet pervasive, markers of historical non-simultaneity" (2014:404). This is a potential weakness in the holograms as an educational tool, since, as Bauer (2012) highlighted earlier, the most integral part of Holocaust education is relevance to the contemporary world of students.

It also appears that the project has not yet focussed on one of the most important aspects of its success, the overall student experience. Kansteiner argues that "any experiments in self-guided immersion in digital violent worlds such as New Dimensions in Testimony must be accompanied by extensive reception studies" (2014:407). The failure to focus on the student's receptive experience is crucial, and unfortunately, it seems this mistake is not limited to New Dimensions in Testimony but occurs often in genocide education, as Gray explains: "in many decades of linear genocide education, we have acquired very little knowledge about actual reception processes, and we are about to repeat that mistake in our lack of study of digital historical cultures" (2014:105). 
Paul Debevec, Professor of Computer Science at USC, who was involved with the project, discusses this technology, emphasizing both its uniqueness and innovativeness, but also reasons for concern: "We lose many of our survivors every year. We definitely feel the sense of urgency and that realistically it's going to be now or never"(Katz, 2013). The challenge is to balance a "now or never" mindset with appropriate consideration of the receptive experience. Attention must be turned to this dilemma. This is a groundbreaking and fascinating way to preserve and present survivor testimony; however, the literature suggests that there are aspects of an impulsive reaction to the the affordances of new 3D holographics technology at a time when Holocaust survivors are passing away. What is needed is a well thought out and planned method of educating future generations using new media technologies.

\section{Geo-Immersion}

Arguably the most innovative of Holocaust education technologies is being developed by the The Integrated Media Systems Center at the University of Southern California, where geo-immersion is used to present computer-generated 'virtual spaces' that show changes over time. Shahabi, Khodaei and Fishbain explain: "4-D 'virtual spaces' are 3-D buildings and places built up from original maps and plans, which change with time, making a fourth dimension. It means that if you view the space as it was in 1940, it will be different from 1944 and very different from the current day" (2012:11). Michael Gray explains that this would "provide a very useful resource for students to see the changes that occurred on a street, in a ghetto or in a concentration camp" (2014:120). 
Using geo-immersion, "we aim to place the testimonies of Holocaust survivors within a 4-D space, such as an interface that would allow a student or researcher to 'walk' through a simulated location - a historical site, for instance - observing how it looked 70 years ago compared to how it looks today, all while listening to relevant testimony about the location and the events that occurred there" (Shahabi et al., 2012;11). Gray asserts that this effort has the ability to "revolutionise the nature of Holocaust education especially outside of the classroom when visiting historical sites. It would offer an unprecedented insight into the past with the potential to integrate the voice of survivors into the exploration of the place which is being discovered" (Gray, 2014;120).

\section{Web 2.0}

Victoria Walden observes that "[w]hen Anna Reading suggested in 2001 that 'the Holocaust has taken on a virtual dimension', she could hardly have predicted the impact digital technology would have on contemporary Holocaust memory" (2015:1). The emergence of social media has enabled contributions of content from a much broader population. Walden explains: "There is a growing number of platforms, in relation to material constructed for users, that enables anyone to contribute to Holocaust memory, including YouTube, Twitter and Facebook" (2015:2). Walden cites the interesting example of a YouTube video titled "I Will Survive Auschwitz." The clip shows a male survivor dancing with his grandchildren at various concentration camps to celebrate his survival. The video received mixed reviews, Walden notes, with "many survivors lambasting it as distasteful, but younger generations celebrating it as the survivor's way 
of remembering his history" (2015:2). Walden makes an important point: that "if the new generation is to be the future authority of Holocaust memory, then to completely condemn its modes of communication is counter-productive. Behind the drive to remember are imperatives to learn from the past and defend against denial. By refusing to engage with young people's preferred methods of communication, we risk discouraging them from engaging with Holocaust memory" (2015:2).

One concern with the work of Reading and Manfra and Stoddard is that it fails to address web content generated by young people, which is an integral part of the digital interactive space and social media. Walden notes that the focus is solely on web content created for young people and "they highlight texts that enable young people to see and hear eyewitnesses, but engage them less in actively contributing to memory" (2015:3).

There are risks here of trivializing the memory of the Holocaust if proper safeguards are not in place. For example, one of the most popular videos about the Holocaust and Second World War on YouTube is from the German movie Der Untergang [Downfall] (2004), which tells the story of the last days of the Nazi regime. A clip of Hitler ranting at his generals for what he believes is their incompetence at preventing the Allied advance on Berlin has been used for all sorts of parodies, so much so that one of Britain's most respected newspapers, The Daily Telegraph, published a guide entitled “Hitler Downfall parodies: 25 worth watching”. Sadly, these videos together have more internet views than any focussing on actual memory of the Holocaust. It is important to conduct research to find out if there is a correlation between such videos and the understanding of the Holocaust among young people. 
Still, social media is a place where students can easily contribute to Holocaust memory in a forum in which they excel. For example, USHMM has over 220,000 followers on Twitter (August 2014). USHMM tweets include important dates and events, and more importantly, they provide interactive question and answer periods enabling students around the world to engage with experts and survivors in real time (Gray, 2014).

It is clear the involvement of young people in actively contributing to memory is important; yet another important concern with social media is that it is being used to effectively spread right-wing extremism and Holocaust denial (Pfanzelter, 2013). Mainstream social media sites such as Facebook have cracked down on such activity, yet in 2010 there were thirty-one Facebook groups with "the denial of the Holocaust as their central or predominant purpose" (Darnell, 2010;32). The members of such groups number approximately 4,853 (Darnell, 2010). Steve Darnell's most concerning finding relates to Google, where "the relative popularity of searches of the term 'Holocaust' has trended downwards since 2004, the relative popularity of searches of 'Holocaust denial' is on the rise. Specifically, over the past year, the use of 'denial' as a related search term to the Holocaust has increased by seventy per cent" (Darnell, 2010;33). Again, this is an important area for research to ascertain if this is because of a rise in interest in 'Holocaust denial", or, hopefully, an increase in concern about the phenomenon of 'Holocaust denial" itself.

Gray (2014) notes that Facebook, a very popular social sharing site with young people, has become a means of Holocaust memorialization. One example is where residents of Lublin, Poland, set up a profile page for Lublin resident Henio Zytomirski, 
murdered at Majdanek in 1942. "Henio" gained over 3,000 Facebook friends (Geras \& Sislowska, 2010). A cousin of Henio's, Neta Zytomirski Avidar, wrote: "Henio was an eyewitness and a victim to the Nazis' actions. Because he was murdered, he could never provide his testimony. We try to guess what might have been his testimony" (Geras \& Sislowska, 2010). This raises some potential concerns. The value of testimony is in its authenticity and verifiable nature. As soon as this is removed, its legitimacy can be questioned. Historian Adam Kopciowski of Lublin's Marie Curie-Sklodowska University cautioned: "This is an act of pretending to be a person that has died, but we cannot be sure whether he spoke that way, whether he thought that way, whether he acted that way" (Geras \& Sislowska, 2010). On the other hand, Joy Sather-Wagstaff, a cultural anthropologist at North Dakota State University argued: "I look at this as a virtual version of what they would leave if they actually went to a place where there was a monument to him.... I bet they would leave little notes and toys - the physical material version of what you see them leaving on Facebook" (Geras \& Sislowska, 2010).

Lublin had one of the highest proportion of Jews in Poland, with a third of the city's population at that time; almost all of its 42,000 Jews were killed in the Holocaust (Poprzeczny, 2004;81). "Henio"'s Facebook profile read: "Forty thousand names and faces ... cannot be memorized," urging people instead to "remember just one of them" (Geras \& Sislowska, 2010). This is an important point because very few people would have ever heard of Henio's story if not for this Facebook initiative. Facebook has recently updated the visibility of deceased users sites to "maintain the visibility of a 
person's content and account as it had been set up by that user allowing Facebook to serve as a public memorial site to people who wanted to share publicly" (Fowler, 2014).

These observations, along with the concerns raised earlier about the outcome of Brown's simulation and the New Dimensions of Testimony project, highlight the real dangers of playing with history through the use of digital technologies. Gray elaborates on the conflicting nature of such instances, explaining they "raise ethical issues about the morality of speaking on behalf of the deceased in the first person, yet they raise awareness of the tragedies which befell the victims, preserve their memories and may educate individuals about their experiences" (2014:115). Engagement with social media raises real issues with regards to Holocaust education, however, there are important opportunities here as well.

\section{Google \& Dynamic Digital Mapping}

In addition to incorporating different types of media from the Holocaust into digital storytelling, it is important to integrate new technologies that can help student understanding in the context of the $21^{\text {st }}$ century and this is exemplified by some of the tools and resources from Google. In 2007, Google partnered with the United States Holocaust Memorial Museum in an "unprecedented online mapping initiative aimed at furthering awareness and action in the Darfur region of Sudan". The project was entitled Crisis in Darfur. The project used Google technology to help users visualize and learn about the events and destruction in Darfur. "The high-resolution imagery in Google Earth 
enables users to zoom into the region to view more than 1,600 damaged and destroyed villages, providing visual, compelling evidence of the scope of destruction" (United States Holocaust Memorial Museum [USHMM] and Google Join in Online Darfur Mapping Initiative, 2007). Not only do such projects benefit the teaching experience but "humanitarian organizations and others now have a readily accessible tool for better understanding the situation on the ground in Darfur" (USHMM and Google, 2007). At the same time, the Museum announced a mapping project on the history of the Holocaust through the program Google Earth. As described on its website, the Museum is using Google Earth to map key Holocaust sites with historic content from its collections, powerfully illustrating the enormous scope and impact of the Holocaust" (Mapping the Holocaust: Google Earth, n.d.). This technology enables the use of maps as visual browsing interfaces for class lessons. The Google Cultural Institute partnered with Yad Vashem to create another fantastic resource in creating an effective online digital storytelling method for teaching the Holocaust. This involved using experimental optical character recognition (OCR), which helped transcribe the text on many of the more than 140,000 images, making them discoverable on the web (Google Cultural Institute, n.d.).

\section{SUMMARY OF THE PROPOSED MODEL}

There exists a large body of digital information and resources on the Holocaust. My research has focused on how to make the best use of this information, along with the objectives of combining different digital technologies to maximize information retention, student engagement, and identification with the events, which is illustrated by a case 
study. This protocol also includes a review of potential strengths and pitfalls of digital technology, along with consideration of ethical issues-a concern present in the education and teaching of emotional and disturbing events such as the Holocaust-in light of a diminishing number of actual survivors and the efforts to preserve their experiences through digital technology.

\section{CASE STUDY}

As an example of the proposed approach, this paper uses the story of Pinchas Gutter. Gutter was born in 1932 in Lodz, a city in central Poland, 135 kilometers south-west of Warsaw. His story stands out for several reasons. First, from a historical perspective, Gutter experienced the early anti-semitic policies of Nazis immediately after their invasion of Poland, he experienced life in hiding in the Warsaw Ghetto, and he survived the Nazi death camps Majdanek and Buchenwald, several forced labour camps, and the death march back into Germany near the end of the war. His story helps students get a profound understanding of what the Holocaust was. Second, Gutter's story is particularly relevant when it comes to the issues of survivors passing away and the integration of digital technology, as Gutter recently took part in the first project involving holographic representation of Holocaust survivors to preserve and share testimony. Third, his story is presented in an impressively interactive way. Gutter spent five days answering no less than 1,800 questions on his Holocaust experience. 
Figure 5: The Digital Storytelling Cube of Pinchas Gutter

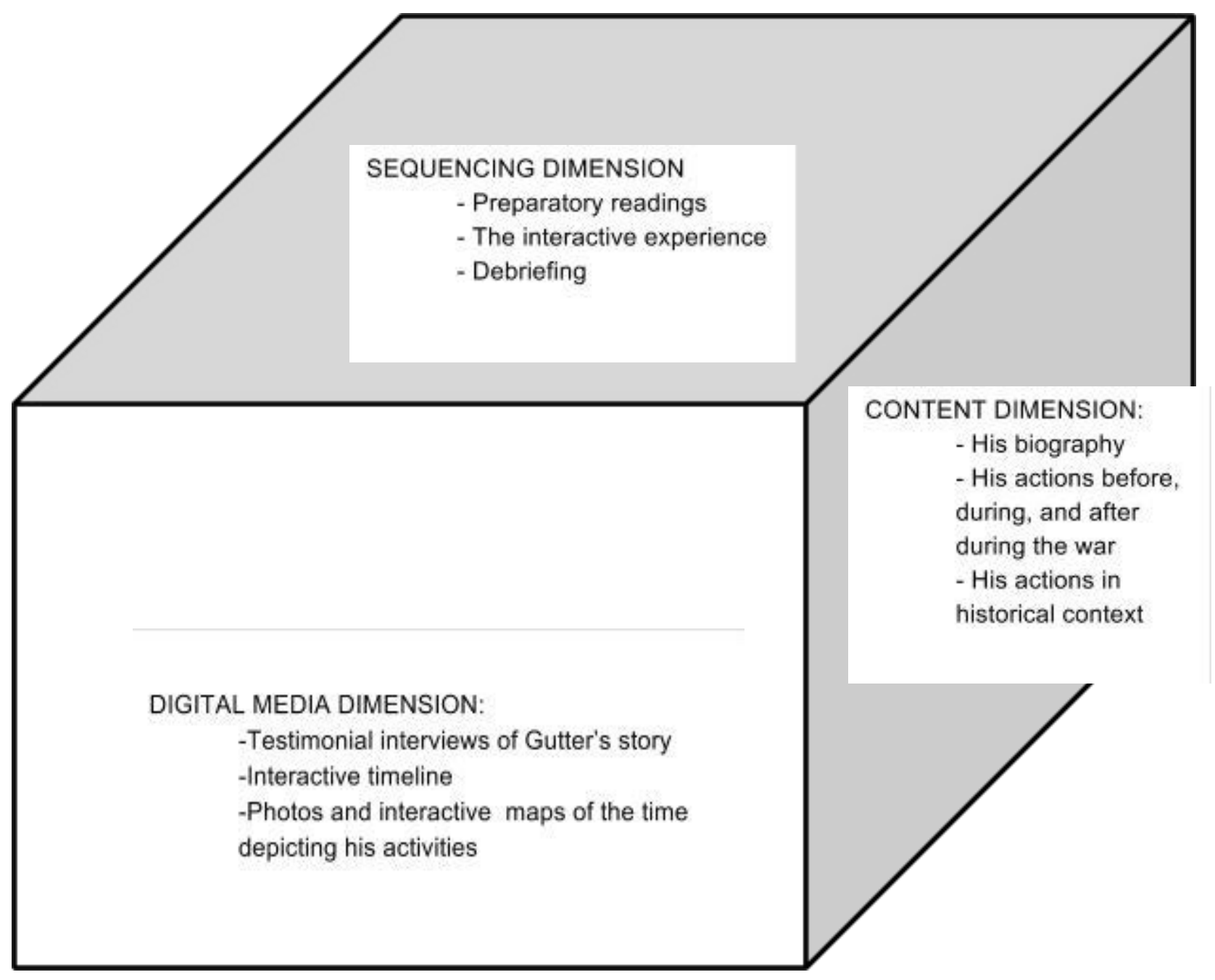




\section{DIMENSION ONE: CONTENT}

The content provides the resources to tell the story. These resources must be used effectively and efficiently. This means just enough content to tell the story without overloading the viewer. In Gutter's case, this is challenging considering so much content is available. It is important to take elements from his testimony that reflect each aspect of his life before, during, and after the war. Fortunately, Gutter's story is documented in detail in a documentary by the Hebrew University of Jerusalem. Gutter retraces his childhood from growing up in Lodz before the war to his liberation at Theresienstadt in 1945. While all this material is valuable, it is unnecessary to show it in its entirety for it to be effective. For example, as Gutter stands in front of his apartment building in Lodz, he tells a story about the Jewish community, describing the scene at the market. Gutter explains tradesmen would constantly shout out offering their services and beggars would ask people to throw them charity from their windows. Gutter recounts how his grandfather would stack money on his window to give to beggars, and when the money ran out, he would go to the kitchen and give them his food. He says "these are the memories he had from living at the place" (Nevo, 2014). This is important evidence for documenting Jewish life in Poland before the Second World War however, it does not necessarily add to Gutter's story in the context of the protocol.

Gutter describes another instance from his childhood that is more appropriate to the context of the lesson. On a Saturday trip with his mother to the local park where Gutter often came to play, a man crossed from the other side of the street, stopped in front of his mother and said "How dare you a Christian young women work for these 
dirty Jews?" (Nevo, 2014). The man was under the impression that Gutter's mother was a non-Jew because of her beautiful blonde hair and blue eyes, while Gutter was dressed in clearly identifiable Jewish religious garb. This illustrates that, despite Gutter's relatively normal childhood, anti-semitism was present.

In addition to selecting important aspects of Gutter's testimony, it is crucial to address the historical context in an engaging way. By using a digital timeline, outlining major historic events leading up to the WWII and the Holocaust, this objective can be achieved. The timeline below is a modified version of The Guardian's interactive WWII timeline (The Guardian, 2009). Modifications have been made to the timeline, including the student's ability to interactively track events on Google Maps, watch relevant videos explaining the events, and clear descriptions of how Pinchas Gutter's story exemplifies this part of history. There are three especially important events (See Figures 6a, 6b, and $6 \mathrm{c}$ on the next page) which need to be emphasized in the content domain in this case example:

1. The first is the Nazi invasion of Poland on September 1st, 1939, marking the start of World War II (WWII). When the Nazis reached Gutter's hometown of Lodz on September 7th, 1939, they almost immediately instituted restrictions on Jews. Gutter, seven years old at the time, describes that Jews were banned from trains, public parks, had limitations on bank withdrawals, and Jewish shops were closed.

2. The second event is the creation of and life in the Warsaw Ghetto. Established in the late 1940's, the Ghetto covered an area 3.4 square kilometers and contained 400,000 Jews. To put the size in perspective, $30 \%$ of Warsaw's population were 
living in an that covered $2.4 \%$ of city. Pinchas Gutter and his family were among them. Between 23 July and 21 September 1942, Grossaktion Warschau (Great Action Warsaw) operation took place. In 1942, at least 254,000 of the Ghetto's inhabitants were sent directly to their deaths at the Treblinka extermination camp. Gutter and his family were in hiding and managed to avoid deportations until 1943 when they were deported to Majdanek where his entire family was murdered.

3. The third event is liberation on May 8th, 1945. After surviving the Warsaw Ghetto, two death camps, multiple labour camps, and the death march, Russian soldiers liberated Gutter at Theresienstadt in Czechoslovakia. 
Figures 6 a, b, and c: Gutter's Timeline
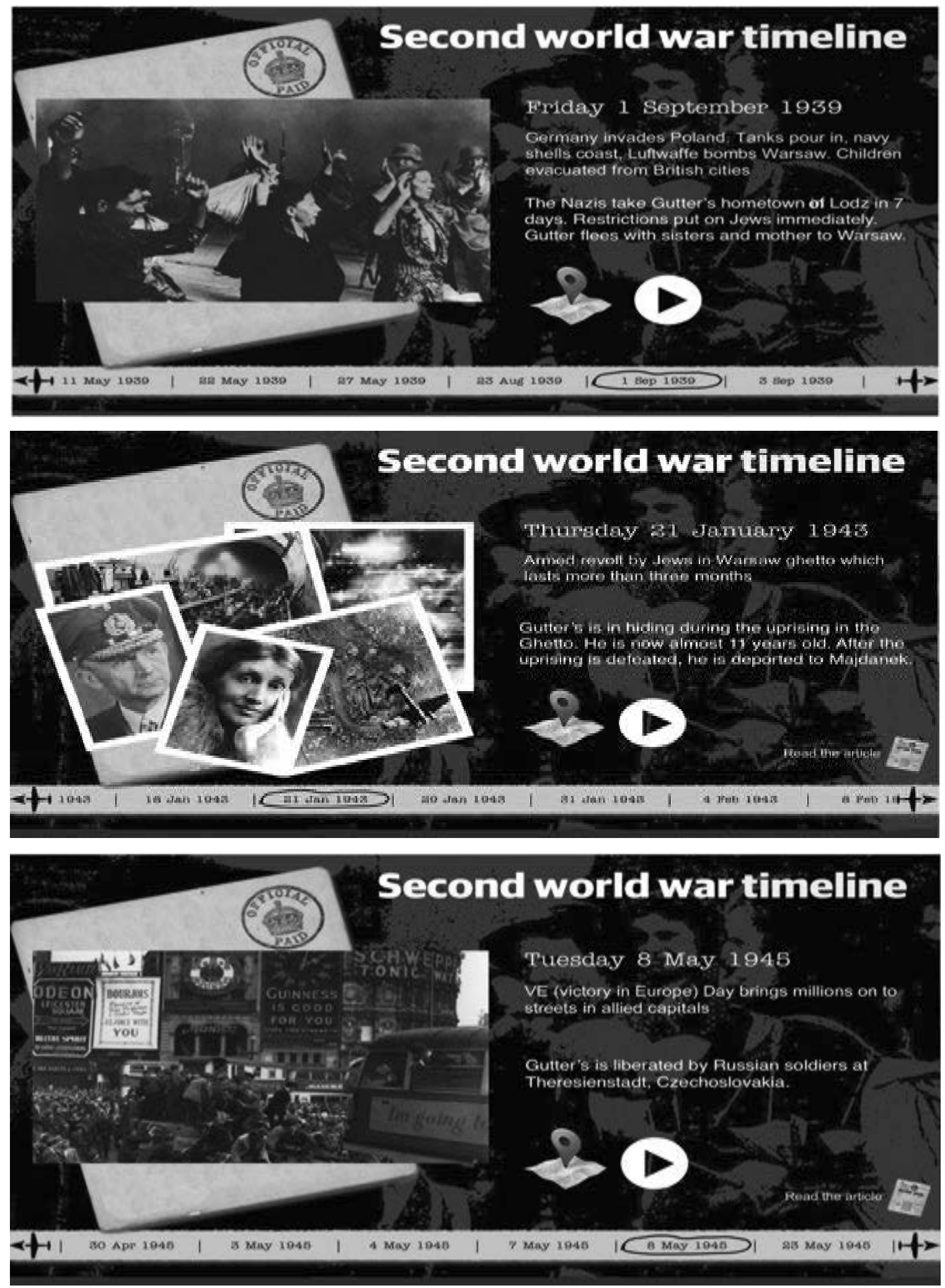


\section{DIMENSION TWO: SEQUENCING}

In the case example, we can verify Gutter's will to survive, through the documented records and survivor testimony. The sequencing of this coverage is one of the most effective means of ensuring student engagement and learning.

Bernard (n.d.) advises that information be presented "when it best serves the story". She explains "if you give away too much information too soon, important details will be lost or their significance missed. Like a good dramatist, you want to introduce characters and seed information in a way that allows the viewer to anticipate the story and its tensions, and ultimately, to resolve them, hopefully before the film does (allowing the viewer the satisfaction of "getting it" and enjoying what's known as an "aha!" moment)".

The suggested sequencing of the story is as follows:

1. Begin with a clip and a quote of a Barack Obama speech citing Pinchas Gutter and his importance.

2. Give the historical context: describe the Nazi invasion of Poland, the Final Solution, Establishment of Ghettos, and deportations to extermination camps.

3. Introduce Pinchas as a child, who he is and where he is from.

4. Let students explore Gutter's journey before and during the War, in the Warsaw Ghetto, at Majdanek, Buchenwald, various work camps, and the death march. This should be followed by a debrief to a address students uncomfort with the content. 
5. Discuss Gutter's life and mission after the Holocaust.

6. Hold a classroom discussion discussing the significance of Pinchas Gutter.

7. Debriefing: Ethical considerations have been stressed as important in the storytelling about the Holocaust. The particular case example chosen is a story of hope and survival. Thus sensitivity to reactions to the story and the opportunity for debriefing are important.

Rationale:

Beginning with the video of Barack Obama is important because he is a recognizable figure of significant stature who highlights Gutter's importance. Obama's popularity among young people is important and his comments are likely to engage students. Next, it is crucial to address the basic historical context to ensure student familiarity with the topic. Steps 2 through 4 are student-focused learning with the guidance of the teacher. This includes the important step of introducing the students to the feature of this case study, Mr. Gutter. It is important to put focus on Gutter's childhood before the war as well in order to understand that Gutter's lived a normal childhood that almost entirely worry free. Still, it is important to tie his childhood experiences with relevant events. Only once this is addressed is it appropriate to move to the fourth stage which is pivotal in student engagement and participation. Students need to be given adequate time to explore the interactive timelines, maps, videos and other digital components. In this stage it is important for students to learn about the horrors of the Holocaust, as terrible as they may be. The power of Gutter's experience and ultimate 
survival is tied to the horrors experienced by millions, from living in the horrible conditions of the Warsaw Ghetto, to surviving death camps and witnessing his family's murder at the gas chambers at Majdanek, watching his friends die in the death march. This is followed by the additional context of Mr. Gutter's life after the Holocaust. Here it important to acknowledge how impressive, courageous and heroic Gutter's survival is but at the same time focus on the post-traumatic experience of the Gutter's survival, which he acknowledges haunts him to the present day. Further, these last two steps are focused on ensuring students can generalize from the specific story to its greater historical significance, followed by ample opportunity for debriefing.

\section{DIMENSION THREE: DIGITAL MEDIA}

This case study provides a very powerful opportunity to make the case for the power and possibility of digital technology and media, and exemplifies the clarity of the proposed template in finding the right balance between the ample digital material available, supplemental historical content and other resources, along with a thoughtful sequencing of the material.

Providing geographic context will help students to understand not just Gutter's personal story, but the history of the Holocaust as a whole. The videos linked here feature Gutter's own testimony at each of the locations he was at during the war.

Though traditional research suggests that students and teachers often misperceive geography as an outdated discipline, more recent research suggests the contrary. Fitchett and Good (2012) cite a report by Segall and Helfenbein (2008) of "efforts by educators to 
advocate a new geography that emphasizes a student-centered constructivism, whereby ‘doing geography' takes precedent over rote practice. These pedagogical positions counter prevailing misconceptions of the role and importance of geography among the social studies disciplines" This concept is referred to as new geography, which "promotes an intertwining of geographical content knowledge, skills, and perspective-taking” (2008:87).

Geographical Information Systems (GIS) is a tool that incorporates geography into the classroom by combining digital mapping and quantitative data to create interactive maps (Fitchett and Good). GIS mapping enable students to discover the corresponding relationship of spatial themes and historical events (Knowles and Hillier, 2008). Interestingly, genocide has become the popular focus of historical GIS efforts in recent years (Manfra and Stoddard 2008; O’Lear and Egbert 2009). Joseph Kirman (2003) suggests that "exposing students to a geographic perspective of genocide elicits a critical dialogue on resulting social and ecological ramifications, thereby encouraging a 'transformative geography"” (Kirman 2003). Fitchett and Good explain "not only does transformative geography challenge students to engage and react to historic and/or contemporary genocide, but it also encourages them to recognize the importance of social justice as a key component of social studies instruction and purpose" (2012:88), while O’Lear and Egbert assert that "employing GIS and geo browser applications affords students the opportunity to conceptualize geography in a more dynamic and inquiry-based manner" (2009:91). 
The interactive mapping framework created for Gutter's story combines GIS with other digital media tools such as YouTube, digitized images and documents in order to create an effective resource for educating students. This resource gives students the ability to explore Gutter's story on their own, with guidance, but not in a traditional “one-size-fits-all, one-way lecture” that Tapscott describes (2009:22).

In spite of the fact that a hologram has been developed of Mr. Gutter, it was decided to deliberately leave the hologram out of the case study. The experience of watching the hologram illustrated some of the very pitfalls that have been discussed in this paper. Mr. Gutter appeared to be "out of this world", and rather than an experience of meaningful interaction with a real person telling a powerful story, it was actually unsettling. It seems premature to integrate such technology into Holocaust education until more work is done bridging the capabilities of the technology with the important objective of communicating a human experience to which students can relate and understand. Gutter's story is powerful and compelling and should be told in an environment that supports his humanity and the story he has to share. This is why the use of proven digital storytelling methods, interactive timelines, dynamic mapping, and video clips were chosen in communicating Gutter's story. More work remains in harnessing the power of digital technology in the context of capturing the human experience of survivors like Mr. Gutter.

\section{SUMMARY AND CONCLUSIONS}

In order to effectively to teach the Holocaust in the 21 st century, it is imperative to use the digital technologies we have at our disposal. Testimony, video footage, 
photographs, film, and art have been important components of Holocaust education for years. However, with the goal of ensuring the ongoing relevance of historic events such as the Holocaust, and in consideration that the passage of time, stories may need to be told long after the survivors have passed on. Digital media provide the ability if not the obligation to make intelligent use of digital resources.

The use of digital media in an integrated protocol such as the one proposed in this paper is also a compelling approach to achieving the goals of student engagement, information retention and facilitating the student's identification with the historic events. As Barack Obama eloquently stated, "by keeping the memories alive, by telling stories, by hearing those stories, we can do our part to fulfill the mitzvah, the commandment of saving a life. I think of Pinchas Gutter, a man who lived through the Warsaw Ghetto Uprising, and survived the Majdanek death camp. Today he serves as a volunteer educator at the Shoah Foundation. In his own words, Pinchas Gutter says it best: 'I tell my story,' he says, 'for the purpose of improving humanity, drop by drop by drop. Like a drop of water falls on a stone and erodes it, so, hopefully, by telling my story over and over again I will achieve the purpose of making the world a better place to live in.' Those are the words of one survivor -- performing that 'sacred duty' of memory -- that will echo throughout eternity. Those are good words for all of us to live by" (Obama, 2014). It is hoped that this protocol will be of use in creating an accurate, enduring and indispensable resource for educating about the Holocaust as an illustration of the power and potential of digital media and technology. At the same time, it is important to recognize the importance of integrating forms of digital media technology in a 
responsible and thoughtful way, taking into account the ways in which the information will be received and processed by the intended audience. In this paper the focus was on students who have an unsurpassed access to and command of digital technology. The vast resources invested into developing these technologies must directly address the pitfalls of assuming that if they are technologically advanced, they will be educationally effective. If we fail at this task, not only will we reduce the effectiveness of Holocaust education, we will also miss the opportunities provided by these powerful technologies and their potential to properly acknowledge and memorialize the experience of Holocaust survivors and other important historic events. 


\section{REFERENCES}

About The Museum - United States Holocaust Memorial Museum. (n.d.). Retrieved from http://www.ushmm.org/information/about-the-museum

Avitecture - Yad Vashem Holocaust History Museum. (n.d.). Retrieved from http://www.avitecture.com/index.php/project-gallery/63-yad-vashem

Bauer, Y. (2012, August 15). Teaching the Holocaust in the 21st century [Video file]. Retrieved from https://www.youtube.com/watch? $v=-x v J V C T Y x p Q$

Baumeister, R. (2002). The Holocaust and the Four Roots of Evil. In The social psychology of the Holocaust: Contemporary analyses of the perpetrators of genocide. New York: Oxford University Press.

Bernard, Sheila Curran. (n.d.). Documentary Storytelling: The Drama of Real Life. Retrieved from http://www.writersstore.com/documentary-storytelling-the-drama-of-real-life/.

Brown, J. G. (2007). Teaching about genocide in a new millennium. Social Education, 71(1), 21.

Busfield, S. (2000, April 11). Irving loses Holocaust libel case. The Guardian. Retrieved from http://www.theguardian.com/books/2000/apr/11/irving.uk

Clark, C. (2012). Children's and Young People's Reading Today: Findings from the 2011 National Literacy Trust's Annual Survey. National Literacy Trust.

Crowe, D. (2001). The Holocaust, historiography, and history. In Teaching and studying the Holocaust, ed. S. Totten and S. Feinberg, 24-61. Boston, MA: Allyn and Bacon.

Darfur conflict. (2014, July 31). Thomson Reuters. Retrieved from http://www.trust.org/spotlight/Darfur-conflict

Darnell, S. (2010). Measuring Holocaust Denial in the United States, (Policy Analysis Exercise, MA: Harvard Kennedy School of Government). 
Fathi, N. (2006, December 10). Holocaust Deniers and Skeptics Gather in Iran. New York Times. Retrieved from http://www.nytimes.com/2006/12/11/world/middleeast/11cnd-iran.html? $\mathrm{r}=0$

Garde-Hansen, J., Hoskins, A., \& Reading, A. (2009). Save as... digital memories. New York: Palgrave Macmillan.

Gray, M. (2014). Contemporary debates in Holocaust education. New York: Palgrave Macmillan.

Gray, M. (2015). Teaching the Holocaust: Practical Approaches for Ages 11-18. London: Routledge.

Green, E. (2014, May 14). The World Is Full of Holocaust Deniers. The Atlantic. Retrieved from http://www.theatlantic.com/international/archive/2014/05/the-world-is-full-of-holocaustdeniers $/ 370870 /$

Hitler Downfall parodies: 25 worth watching. (2009, October 6). The Telegraph. Retrieved from http://www.telegraph.co.uk/technology/news/6262709/Hitler-Downfall-parodies-25-wort h-watching.html

Hollinger, A. (2007, April 10). United States Holocaust Memorial Museum and Google Join in Online Darfur Mapping Initiative. Retrieved from http://www.ushmm.org/information/press/press-releases/united-states-holocaust-memoria l-museum-and-google-join-in-online-darfur-ma

Irving v. Lipstadt, (2000), High Court of Justice of England and Wales - Queens Branch 115

Kansteiner, W. (2014). Genocide memory, digital cultures, and the aestheticization of violence. Memory Studies, 7(4), 403-408.

Katz, L. (2013, February 11). Holograms of Holocaust survivors let crucial stories live on. CNET. Retrieved from http://www.cnet.com/news/holograms-of-holocaust-survivors-let-crucial-stories-live-on/ 
Knowles, Anne Kelly, and Amy Hillier. (2008). Placing history: How maps, spatial data, and GIS are changing historical scholarship. Redlands, CA: ESRI Press.

Koren, D. (2015, January 29). BBC asks if it's time to stop talking about Holocaust. Ynet News. Retrieved from http://www.ynetnews.com/articles/0,7340,L-4620177,00.html

Lambert, J. (2012). Digital storytelling: Capturing lives, creating community. London: Routledge.

Lester, P. (2013). Digital Innovations for Mass Communications: Engaging the User. London: Routledge.

Lipstadt, D. (1993). Denying the Holocaust: The growing assault on truth and memory. New York, N.Y.: Plume.

Lipstadt, D. (2006). History on trial: My day in court with a Holocaust denier. New York: Harper Perennial.

Maio, H., Traum, D. and Debevec, P. (2012). New Dimensions in Testimony. Past Forward, Summer 2012, 22-26.

Manfra, M. M., \& Stoddard, J. D. (2008). Powerful and authentic digital media and strategies for teaching about genocide and the Holocaust. The Social Studies, 99(6), 260-264.

Maryann Kiely Lovelace. (2005). Meta-Analysis of Experimental Research Based on the Dunn and Dunn Model. Journal of Educational Research, 98(3), 176-83.

Mapping the Holocaust: Google Earth. (n.d.). Retrieved from http://www.ushmm.org/learn/mapping-initiatives/mapping-the-holocaust-google-earth

Nevo, Z. (Director). (2014). Political, Polish Jew: The Story of Pinchas Gutter [Motion picture]. Israel: Hebrew University of Jerusalem.

Newmann, F. M., \& Wehlage, G. G. (1994). Five standards of authentic instruction. Annual editions: Educational psychology, 94-95. 
Obama, B. (2014, May 7). Remarks by the President at USC Shoah Foundation Dinner. Retrieved from

https://www.whitehouse.gov/the-press-office/2014/05/07/remarks-president-usc-shoah-fo undation-dinner

Ochayon, S. (2015, March 26). Using Holocaust Testimony in the Classroom [Video file]. Retrieved from https://www.youtube.com/watch?v=vGx-8oMuOsk

O'Lear, Shannon, and Stephen L. Egbert. (2009). Introduction: Geographies of genocide. Space and Polity 13 (1): 1-8.

Pfanzelter, E. (2013). 'The Holocaust and Social Networks: Memory, Commemoration or Forums for Anti-Semitism and Racism?' Paper presented at The Future of Holocaust Studies Conference, Universities of Southampton and Winchester, 29-31 July 2013.

Poprzeczny, J. (2004). Odilo Globocnik, Hitler's man in the East. Jefferson, N.C.: McFarland.

Reading, A. (2003). Digital interactivity in public memory institutions: the uses of new technologies in Holocaust museums. Media, Culture \& Society, 25(1), 67-85.

Shahabi, C., Khodaei, A. and Fishbain, B. (2012). Geo-Immersive Learning, Past Forward, Summer 2012, 11-12.

Tapscott, D. (2009). Grown up digital: How the net generation is changing your world. New York: McGraw-Hill.

Walden, V. G. (2015). New Ethical Questions and Social Media: Young People's Construction of Holocaust Memory Online.

Yad Vashem Archive. (n.d.). Retrieved from http://www.yadvashem.org/yv/en/about/archive/about_archive_whats_in archive.asp

Yad Vashem - Cultural Institute - Google. (n.d.). Retrieved from http://www.google.com/culturalinstitute/about/yadvashem/ 